\title{
The ionosphere detector transmitter failure analysis
}

\author{
Zhang Xuezhi ${ }^{1}$, Xie Cun $^{1}$,Tang Xiaokang ${ }^{1}$, Zou Qiong ${ }^{1}$, Ma Yongshan $^{2}$
}

\section{Wuhan Mechanical Technology Colledge, Wuhan, China 2.The 65370 \\ Department,Changchun, China}

Key words: fault phenomenon; The transmitter; Fault diagnosis

Abstract: the ionosphere detector is the ionosphere detection equipment, its can be long-term, effective and stable operation, relationship can effectively the ionosphere normal detection. Therefore, it is imperative to research on fault diagnosis of the ionosphere detector, this paper mainly analyses its transmitter, find out the common fault phenomenon and the possible reasons, lay the foundation for the next step research.

\section{Summary of transmitter}

The ionosphere detector transmitter consists of actuator, power amplifier unit transmitter malfunction ionosphere detectors will not work properly. Transmitter for solid state transmitter waveform partly integrated in the system host, detecting signal generated by the excitation source and then to enlarge shortwave power amplifier output, through the antenna radiation outward. Transmitter system, therefore, fault fault is divided into waveform and power amplification. Waveform in DDS\&FPGA module, the module failure state of the ionosphere instrument panel will report to the police. Failure in this section, a detailed analysis of a transmitter power amplifier, power amplifier is mainly composed of power amplifier unit, display control unit, power supply units.

For all solid state transmitter power amplifier unit is its core components, each power amplifier unit design have complete protection function: motivation, overload, overheating protection. When the fault occurs, a fault on the host LED screen display, as well as audio alarm, and on each power amplifier and the corresponding failure indicator display.

\section{Normal work flow transmitter}

Power failure: first check the input control signals in the power amplifier is working correctly then inspect of switch power supply $+24 \mathrm{v}$ and $+50 \mathrm{v}$ output voltage is normal;

Description: as a transmitter of switch power supply damage 1, for the transmitter, a total of two switching power supply, so the transmitter power amplifier unit cannot provide current, gain is reduced.(2) transmitter power amplifier is $4 * 300$ w power amplifier is one or more smaller power amplifier output power, will cause the driver output power, power amplifier into overload protection, $4 * 300 \mathrm{w}$ power amplifier power output decreases reason mainly has the following four:

Step 1:4* $300 \mathrm{w}$ power amplifier grid voltage $+24 \mathrm{v}$ voltage is not stable, adjust the position of the micro switch power amplifier gain knob can eliminate this phenomenon; 
Step 2:4* $300 \mathrm{w}$ power amplifier grid voltage is zero, may be caused by poor contact. Check method for the micro switch contact reeds, and check whether there is a obvious elastic, or be replaced;

Step 3:4 * 300 w power amplifier power amplifier tube failure, switch on power check the temperature of the pipe work after five minutes, not the power amplifier tube temperature is the damage of power tube, and replaced;

Step 4:4 * $300 \mathrm{w}$ power amplifier at the input attenuator damage or aging, check instrumentation amplifier gain or measure is proposed.theoretical attenuator;

(3) power synthesizer or in passive components of losses, falling of power amplifier gain;

(4) the directional coupler output component or monitoring unit detection circuit problems, detection voltage smaller, higher power output of the actuator, power amplifier in overload protection。

Case 2: power decrease or no input power.

Step 1: check waveform output device's output and input connection cable is normal;

Step 2:4 * 300 w power amplifier inside four possible decline or no current;

A fall in the third step: the power synthesizer output power, check whether the antenna matching impedance of $50 \Omega$;

Step 4: check the ALC control circuit, check the load feeder cables.

Case 3: the "power" indicator, due to the output power is too large. Detect whether the input signal is too large, if the input signal is normal, reverse adjust knob on the front panel power, decrease the gain of the amplifier with reset signal can make the normal work of the amplifier.

Case 4: a "mismatch" indicator, due to the excessive standing wave ratio of the amplifier. Check whether the output of the amplifier to connect $50 \Omega$ load, if the connection is normal, please check the connection cable box of load are in good condition.

Case 5: "overheating" indicator, power amplifier on the cooling temperature is too high. Detection amplifier of the fan is running normally, or whether the temperature relay amplifier.

Case 6: "overpressure" indicator, dc power supply voltage is too high or too low. First check to see if there is that all the blown fuse, if any, can be changed into the corresponding insurance. If insurance is in good condition and good contact, check whether there is a corresponding line contact is not good or directly to check the power output of $50 \mathrm{v}$ and $24 \mathrm{v}$ voltage is normal, if the power supply output voltage must replace the power module.

Case 7: "flow indicator", the current dc power supply. Check whether there is a metal object in the circuit, or whether the power cord aging caused by adhesion short circuit.

Case 8: transmitter panel power rf indicator light is normal but yellow light is not caused by power amplifier module failure. Its failure may appear in the power amplifier module may also appear in the radio frequency (rf) channel. 
Case 9: normal have incentives to signal transmitter power input single without rf signal output 。

Failure analysis: the ionosphere detectors after startup, transmitter phone indicator light is normal, have incentives to signal input that failure occurs in the transmitter power amplifier module.

The cause of the problem: (1) the former level linear amplifier failure; (2) $4 * 300$ w linear amplifier failure; (3) power divider fault; (4) power synthesizer fault; (5) fault directional coupler.(6) check the presence of rf output power; (7) look for rf output directional coupler.

\section{References}

[1] Ma Jian-mei. Environmental art course teaching mode reform of professional landscape design [J]. Anhui Agricultural Science. 2011 (31)

[2] Tang Jun. The development of modern landscape design present situation and trend analysis [J]. Chinese Gardening Abstract. 2012 (9) : 97-2012.

[3] Han Yu. Experience type teaching, the landscape design course teaching practice research [D]. Nanjing: Nanjing College of Art. 2012

[4] Xiang Xiaoxiao. Environmental art professional teaching reform of landscape design study [J]. Journal of Nanchang Institute of Education. 2013 (4)

[5] liu Chun-bo . Analyses of landscape environmental art [J]. The Young Writer. 2010 (18) 